\title{
COMPARING FIRE PROTECTION AND IMPROVEMENT VALUES AT FOUR MAJOR US NATIONAL PARKS AND ASSESSING THE POTENTIAL FOR GENERALIZED VALUE CATEGORIES
}

\author{
D. RIDEOUT ${ }^{1}$, J. LOOMIS ${ }^{2}$, P. ZIESLER ${ }^{1} \&$ Y. WEI ${ }^{1}$ \\ ${ }^{1}$ Department of Forest and Rangeland Stewardship, Colorado State University, USA. \\ ${ }^{2}$ Department of Agricultural and Resource Economics, Colorado State University, USA.
}

\begin{abstract}
A new approach was used to elicit relative values of a variety of natural and cultural resources to estimate the extent that managers thought these resources would be enhanced or harmed by wildfire. This method, while based on economic principles of utility, does not involve monetary valuation. The method is illustrated by elicitation of relative values of different forest types, wildlife habitat and archaeological/cultural resources from resource professionals and managers in Grand Canyon, Rocky Mountain, Sequoia-Kings Canyon and Yellowstone National Parks. While these elicitations were independently performed for each park, the relative protection and improvement values of the various resources are remarkably similar. This similarity may reflect the common and well-focused mandate that national parks operate under. The management implications of the protection and improvement values of natural and cultural resources for wildland fire management at these and other national parks are discussed.
\end{abstract}

Keywords: Disturbance, Grand Canyon, Rocky Mountain, Sequoia-Kings Canyon, value elicitation, wildland fire, Yellowstone.

\section{CHALLENGE OF OBTAINING RELATIVE VALUES OF NATURAL RESOURCES}

For decades, natural resource managers have desired a method that would allow them to directly compare disparate incremental values of varied natural resources they must deal with. This is especially the case when public officials are faced with addressing disturbances, such as wildland fire, hurricanes or insect infestations. Disturbances may disrupt the flow of goods and services from natural systems and can jeopardize life and property values. Wildland fires are disturbances that affect the flow of nature's services over time and they are of particular interest because they can be actively managed before (e.g. fuel treatments), during (e.g. suppression and herding) and after (e.g. rehabilitation) their occurrence. While each fire is unique, any single event can produce a mix of effects inside and along the fire perimeter, depending on the resources affected and the intensity of the burn.

In 2008, the US federal government spent approximately $\$ 3.0$ billion on wildland fire suppression and related activities and another $\$ 3.25$ billion [1] on fuel treatment. In some federal agencies, expenditures on managing fire disturbance now comprise a majority of the agency budget. Concurrently, the US federal interagency implementation guidelines recently evolved to encourage management for multiple objectives:

'A wildland fire may be concurrently managed for one or more objectives and objectives can change as the fire spreads across the landscape. Objectives are affected by changes in fuels, weather, topography; varying social understanding and tolerance' [2].

With scarce resources and increasing importance ascribed to managing multiple objectives, information on the relative marginal values of fire-affected resources is timely and can guide resource management decisions to better outcomes. 
Evaluating fire effects on ecosystem services is also challenging because many of the affected resources are 'non-market' and have attributes of public goods. Samuelson [3,4] first rigorously defined public goods as having the characteristic that once a good is provided, exclusion of beneficiaries is difficult and the benefits are freely available to all. Further, the benefits of public goods are non-consumptive so that one person's enjoyment does not detract from others' enjoyment. Provision of clean air over a city is a typical example of an environmental public good and protection of the geological wonders through national parks, such as Grand Canyon and Yellowstone, is another. Wildland fire can affect the full range of ecosystem services, any of which have public good attributes. For example, high-intensity fires negatively impact water quality and wildlife habitat, both of which have elements of public goods.

Since the publication of Samuelson's work on pubic goods [3,4], resource economists have laboured to develop the theory and techniques of resource valuation. Today, there are many formal techniques for assessing environmental values, including the 'Contingent Valuation Method', the 'Travel Cost Method' and 'Conjoint Analysis' [5]. These and other advances in the theory and practice of resource valuation rely on advanced analysis, are time intensive and are costly to implement. Despite great strides in valuation theory and empirical measurement techniques, land managers continue to face a scarcity of existing information regarding marginal valuation of several natural resources affected by fire (e.g. cultural resources). There have been few applications of economic valuation methods to wildland fire disturbance [6].

Nonetheless, public officials are required to make quick mitigation or enhancement decisions that involve protecting incremental resource values when managing fire events or planning for fuel treatments. Managing the impacts of wildland fire is a required and unavoidable daily occurrence for public officials during the active fire season. Techniques that managers and planners can directly apply to the wide spectrum of resources affected by disturbances could support decision making at the local planning unit level. Marginal relative values, like those reported here, can serve as an important guiding force in resource allocation. For example, a fire planner charged with implementing a fuels treatment programme may have to choose either treating hectares of a particular wildlife habitat or improving the ecological condition of a fire-dependent species. Other things being equal, the relative values of fire effects can guide this decision to improve the effectiveness of the fuels programme. If the marginal value of improving wildlife habitat were twice than that of the fire-dependent species, cet. par., the better decisions will involve increased allocation of treatment funds to the wildlife habitat. Similarly, many decision support systems that rely on mathematical programming techniques (linear programming, mixed integer programming or goal programming) are often burdened with estimating valuation coefficients in the objective functions or constraint sets. This problem is particularly acute when confronted with a mix of market values, for which information may be available, and non-market values that are typically not available. When marginal relative values or their ranges are known, they can be reflected in programming coefficients to produce more credible and effective results.

\section{ONE SOLUTION TO THE VALUATION CHALLENGE}

To address the issue of providing incremental resource values for fire management planning, Rideout et al. [7] recently developed an approach to estimate marginal relative values of natural resources at the planning unit level. The approach, known as 'Marginal Attribute Rates of Substitution' (MARS), requires a structured elicitation of values from fire and 
resource management officials at the local planning unit level. MARS was successfully applied at the Sequoia and Kings Canyon National Parks (SKNP) in May 2005. The MARS process required about 2 days of intense elicitation, and the information supplied through MARS was used to inform fire management and fire-fighting efforts on the SKNP landscape during the 2008 fire management season.

This paper reports on efforts to apply MARS at Grand Canyon (GCNP), Yellowstone (YELL) and Rocky Mountain (RMNP) National Parks as well, to yield a new four-park data set of marginal valuation information. The entire valuation process for each park took about 2 days. Each park was visited and the data were collected between 2005 and 2010. The four parks include famous national treasures and each has important fire and resource management issues requiring information on marginal valuation. The addition of these three parks provides an interesting set of valuation data that addresses important differences among the ecosystems and the extent of variation in values across the ecosystems.

The remainder of this paper describes key elements of MARS as applied to four national parks, compares the results and draws conclusions about the use of MARS and the results to fire management at these and other national parks. Application to four parks and the comparison of values address two fundamental questions: (a) can site-specific relative values of natural resources be elicited (that are consistent with economic principles of utility trade-offs, but without monetary valuation) in a way that suggests a set of generalized values and (b) how similar are the relative values across these four national parks? The first question suggests that while specific marginal values were elicited separately from officials at each national park, does consistency in their implicit prices suggest generalized value categories that transcend the individual parks? The second question addresses the extent of variation in values across parks, recalling that MARS was applied at different locations and with different sets of park management officials. While we investigate these issues with regards to national parks, the MARS method has applicability to other types of public lands, such as national wildlife refuges and national forests and potentially to international refuges and parks. MARS offers another valuation option for fire managers focused on the marginal impacts of fire on property and natural resource values.

However, MARS is not intended to replace traditional non-market valuation methods. Traditional valuation methods have important advantages for comparing monetized benefits with costs and for addressing the assessment of total value, including consumer surplus; both of which are unavailable in the MARS method. Marginal values for fire protection and improvement elicited from MARS are distinguished from measures of total value or of consumer surplus often associated with the Contingent Valuation Method (e.g. Shrestha et al. [8]). Specifically, estimating the relative marginal values of fire protection and improvement does not imply nor require knowledge of the total value of any of these natural or human resources. If such total valuation is needed for comparison to total costs of fire management actions, then traditional non-market valuation methods are needed. However, because managing agencies have limited budgets, they are required to evaluate trade-offs in resource allocation, and marginal valuation can be a useful guiding force in fire planning and management.

\section{DATA SOURCES AND METHODS}

Rideout et al. [7] found that the valuation problem for disturbances, such as wildland fire, differs from direct valuation of the resource. The valuation problem for wildland fire focuses on the change in resource value attributable to the fire effect. This is also known as net value 
change (NVC) in the fire literature and it is monotonically related to MARS estimates [7]. While it is unnecessary to know the total value of the affected resource(s), it is necessary to estimate the change in value due to disturbance to consider the marginal value product of fire management effort. Because value changes associated with disturbances are rarely collected or documented in land and resource management planning processes, marginal valuation estimates for fire management purposes were elicited from managers at each of the four national parks.

\subsection{Case study parks}

The SKNP, located in the Sierra range in southern California, contain the unique and famous sequoia groves, including 'named trees' of special importance, such as the 'General Sherman' tree and the Grant Grove. Although they are a combination of two parks, they are administered and managed comprehensively. Sequoias are a fire-adapted species with thick bark to protect them from low-intensity fire events. The fire-return interval for sequoias is relatively short at approximately 17 years. Frequent low-intensity fires in the groves provide benefits by clearing out encroaching vegetation and removing fuels that could ultimately produce a catastrophic event. The parks are also home to other forest cover, such as the 'mixed conifer' type. Mixed conifer is known for its longer fire-return interval, thin bark and abundant ladder fuels. Ladder fuels enable fire to travel up trees into the crowns where they often increase in intensity, rapidly spread and are difficult to control. SKNP is also home to a ponderosa pine cover type. Although not unique like sequoia, ponderosa pine with its thick bark shares many fire behaviour and fire effect characteristics with the sequoia.

GCNP located along the Colorado River in Arizona shares some similarities with SKNP. Both parks have highly valued cultural resources that are affected by fire and management activities. There are also important differences between the parks in that GCNP does not have the same topographical profile as SKNP and GCNP is home to tree types and wildlife not present in SKNP, such as the pinyon-juniper (PJ) cover type and the goshawk.

In contrast, RMNP and YELL are located in the high elevation rocky mountains and are known for their long fire-return interval cover types. Consequently, they contain different fire-adapted species than SKNP or GCNP. RMNP is located in northern Colorado and contains the headwaters of the Colorado River that ultimately flow through GCNP. YELL is located in north-western Wyoming and is famous for its geothermic sites and variety of wildlife. Similar to SKNP and GCNP, these parks contain a mixed conifer type, but they also have vast stands of lodgepole pine. The lodgepole pine, while fire adapted, responds differently than the sequoia or the ponderosa. Fires in lodgepole pine are often referred to as 'stand replacing' because entire stands are usually consumed and then regenerated by wildfire. Lodgepole pine trees commonly have serotinous cones that, when exposed to heat, burst open to shoot seed on the forest floor to aid with reproduction. Such similarities and differences in vegetation types between the parks make for the informative pairwise comparisons.

\subsection{Value elicitation using the MARS method}

Application of MARS [7] separately to each park entailed assembling a full set of NPS fire management planners from each park to form an 'expert' group for that park. The expert group included resource management specialists, cultural resource specialists, fire management operations specialists and land management planners. As a group, they were responsible 
for the knowledge and management of fire effects on property and natural resource values. Guided by the goals and objectives from their land and fire management plans, and by taking a landscape level perspective, they identified the list of natural resources that they actively manage for positive and negative fire effects. This was expressed as a set of value attributes appropriate to their park. Value attributes are a specific type of resource affected by fire, such as highly valued development areas, sequoia groves (SKNP only) or lodgepole pine cover type (YELL, RMNP). Cover types often serve as a proxy for a set of resources associated with the cover.

As appropriate, the value attributes were further categorized by ecosystem condition and fire intensity. Identifying ecosystem condition and fire intensity categories is necessary when the importance of fire effects differ by intensity or ecosystem condition. The maintenance condition implies that the site is currently in a desirable state that the manager would like to maintain, and restoration denotes a condition that the manager would prefer to change to maintenance. Many ecosystems are dependent upon or can benefit from the introduction of fire, and fire is one tool used to transform an ecosystem from a restoration condition to a maintenance condition. For example, sequoia groves and ponderosa pine stands typically benefitted from low-intensity fire when ecosystems are in a maintenance condition (no missed fire intervals), while the same site might be harmed by high-intensity fire. MARS was specifically designed to admit and integrate the negative and the beneficial effects of fire; in particular, it permits managers to capture the management concept that low-intensity fires may be used in certain cover types to maintain the system in a desirable state. Once the collection of value attributes is elicited and categorized by condition and intensity, the entire list was carefully reviewed by the expert group to ensure that it is complete, appropriate for strategic planning and that it does not include any double counting (identifying the same resource value under two headings).

The final part of the structured elicitation process requires the expert group for each park to estimate the marginal values of each attribute for each fire intensity and ecosystem condition. These marginal values are known as marginal rates of substitution in the economics literature. They indicate the rate at which one value can, in principle, be substituted for any of the others per unit area. In MARS, a value of -1.0 defines the most important resource to protect (per hectare) from fire and a value of -0.5 defines a resource and condition that is half as important per hectare. Positive values, from 1.0 to 0.1 denote beneficial fire effects. They are interpreted similarly and symmetrically with the negative values. These rates of substitution are the key valuation information produced from the MARS process, and because they use a common currency (protection of highly valued developments) they enable comparisons across planning units and within a national park.

\section{RESULTS AND GENERALIZED VALUE CATEGORIES}

The results for the four park set of values and their rates of substitution are addressed starting with anthropocentric resources, such as developments, and followed by natural resources, such as wildlife. Values were elicited for the ecosystem maintenance condition at high- and low-fire intensities for each park, and for ecosystem restoration condition at high- and low-fire intensities for SKNP and GCNP. Table 1 shows each value that was elicited and the park that reported it. It also shows the generalized categories that are further organized by fire intensity and ecosystem management condition in Table 2 . Table 2 also provides the original elicited values from each park organized by fire intensity and management condition. 
Table 1: Fire management meta-value attribute categories for four US national parks.

\begin{tabular}{lcccc}
\hline & \multicolumn{3}{c}{ U.S. national park } \\
\cline { 2 - 5 } Generalized value categories & SKNP & GCNP & YELL & RMNP \\
\hline High-value development & $\mathrm{X}$ & $\mathrm{X}$ & $\mathrm{X}$ & $\mathrm{X}$ \\
Sensitive boundary & & $\mathrm{X}$ & $\mathrm{X}$ & $\mathrm{X}$ \\
Short-return interval cover types & $\mathrm{X}$ & & & \\
Sequoia & $\mathrm{X}$ & & $\mathrm{X}$ & $\mathrm{X}$ \\
Ponderosa pine & & & $\mathrm{X}$ & $\mathrm{X}$ \\
Long-return interval cover types & & & $\mathrm{X}$ \\
Spruce-fir & & & & \\
Lodgepole pine & & & $\mathrm{X}$ \\
Mixed conifer & $\mathrm{X}$ & & & \\
Cultural and archaeological sites & & $\mathrm{X}$ & \\
Cultural trees & & & \\
Cultural sites & & $\mathrm{X}$ & \\
Sensitive archaeological sites & & & \\
Wildlife habitat & & & \\
Goshawk & & & \\
Mexican spotted owl & & & \\
Elk winter range & &
\end{tabular}

Defining a generalized value category is straightforward when multiple parks have identified the same value attribute, such as highly valued development, with the same or similar marginal value. For example, goshawk nesting sites and Mexican spotted owl habitat in GCNP and winter elk habitat in RMNP are consistent with the broader concept of wildlife habitat, suggesting the potential to combine them to form a general category. Other unique attributes may be compared across parks if they relate well in broader categories. In contrast, unique values, such as protection of volcanic monitoring sites in YELL, were not useful because they do not meaningfully compare or contrast with value attributes in other parks.

\subsection{Highly valued development}

Highly valued development was reported for each of the four parks at each combination of fire intensity (high and low) and management condition (restoration and maintenance). Highly valued development includes houses, visitor centres, lodges and other commercial and non-commercial development. Such development consistently had the highest importance to protect from wildland fire (all -1.0) and this reflects the current federal fire policy [9] that places the highest priority on life and property protection. Highly valued development exemplifies a 'direct use' value that has been commonly found to have great influence on valuation in meta-analysis studies [10]. This value attribute appears at each park with the same protection value enabling it to serve as a common currency. The importance of the common currency is that it enables comparisons of relative values across the parks. 
D. Rideout et al., Int. J. of Safety and Security Eng., Vol. 2, No. 1 (2012)

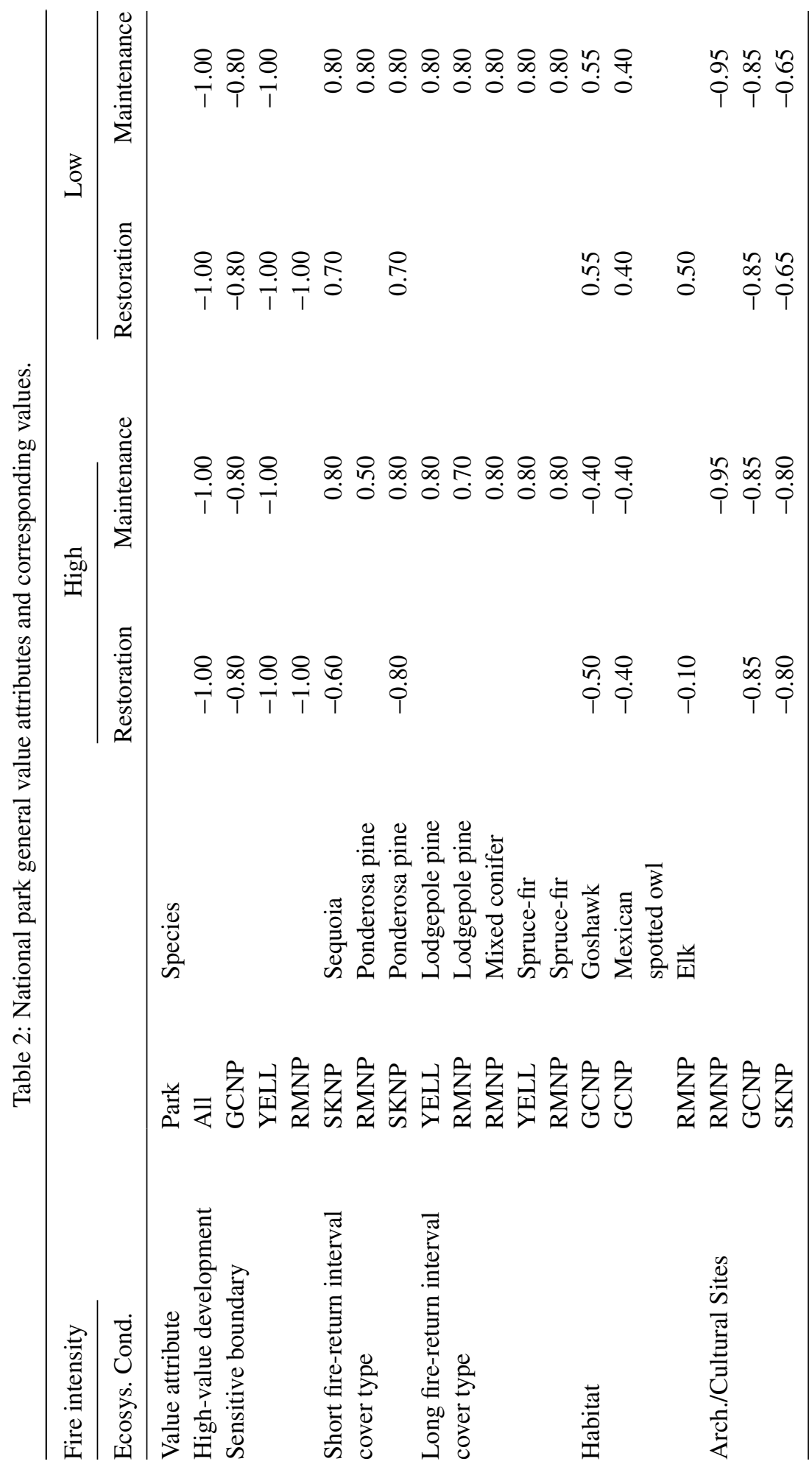




\subsection{Sensitive boundaries}

Sensitive boundaries were identified by GCNP, YELL and RMNP as an important value to protect for both management conditions and fire intensities. Sensitive boundaries include adjacency to other federal, state or county lands or to private ownership. Protection of park boundaries, particularly boundaries near the Wildland-Urban Interface, were expected to be of high importance to protect from fire because they are often a proxy for protection of highly valued development in adjacent ownership. The elicited boundary values in each of the three parks were near -1.0 as expected. YELL reported a value of -1.0 for all four combinations of management condition and intensity and GCNP reported -0.80 for all four combinations, while RMNP reported a sensitive boundary value of -1.0 for the restoration management condition at both fire intensities.

\subsection{Archaeological and cultural sites}

Archaeological and cultural sites were identified by SKNP, GCNP and RMNP as important to protect through fire management. For all combinations of management condition and fire intensity, the values ranged from -0.65 to -0.95 . SKNP recorded the lowest values $(-0.65)$ for low-intensity fires in both management conditions and -0.80 for high-intensity fires (both management conditions). GCNP had the same value, -0.85 , for all four combinations of intensity and management and RMNP had the highest value, -0.95 , for both high- and low-intensity fires in maintenance (no values for restoration).

\subsection{Wildlife habitat}

Wildlife habitat considerations differed at each park and some were identified to have fire-sensitive habitats. Two parks identified wildlife habitat areas that are affected by fire management: RMNP identified elk winter habitat and GCNP identified goshawk and Mexican spotted owl habitats. Values elicited for individual species in each park show that there are similarities among the values, even though the species differ. For example, all wildlife values for low-intensity fires, whether in maintenance or restoration, were positive. This indicates that both parks consider low-intensity fire as generally beneficial for selected wildlife. Importance to improve values for low-intensity fires ranged from 0.40 for the Mexican spotted owl habitat to 0.55 for goshawk habitat. RMNP was in the middle to high range with 0.50 for elk habitat. For high-intensity fires, such values were negative. The importance to protect habitat from high-intensity fires had a wider range than the importance to improve values. For example, RMNP recorded an importance to protect value for elk habitat of -0.1 , while GCNP recorded -0.4 for Mexican spotted owl habitat and -0.5 for goshawk habitat. These moderate values indicate that wildlife habitat is about half as important to protect as high-value developments during high-intensity fires.

\subsection{Short-return fire interval forests}

Short-return fire interval forests were similar across parks in that they often benefit from frequent fire return at low intensity and they can quickly degrade into a restoration condition where controlling fire is problematic and expensive. Similarities at SKNP and RMNP are interesting as they both have ponderosa pine attributes; however, only SKNP has sequoia 
groves. Fire occurring at low intensity in the maintenance management condition provides an interesting comparison between the two parks. Low-intensity burning in maintenance was assessed to have a high benefit with sequoia groves at 0.8 and ponderosa pine (both parks) at 0.80 . SKNP has restoration values reflecting negative effects at high intensity $(-0.6$ for sequoia and -0.8 for pine) and benefits at high intensity ( 0.7 for sequoia and pine). When viewed as a group, all short-return interval values were positive except when in a highintensity restoration condition. High-intensity fires in stands in restoration would be harmful, while other fires are beneficial.

\subsection{Long-return fire interval forests}

Long-return interval forest types were reported at YELL and RMNP in the lodgepole pine and spruce-fir and at RMNP in the mixed-conifer type. All long-return interval forests for these parks were considered to be in a maintenance condition. Among the parks with longreturn interval forests, very similar values were elicited for importance to improve with fire when the stands are in a maintenance condition. All of the elicited values for both high and low fire intensity are 0.8 , except for lodgepole pine in RMNP at low fire intensity $(0.70)$.

\section{SIMILARITIES AND DIFFERENCES IN VALUATION}

Figure 1 illustrates the generalized value categories with their ranges and midpoints from Table 2. Immediately apparent in the figure are similarities across the generalized categories. For anthropocentric and natural resources, the range of generalized value attributes in any management condition or intensity combination did not cross zero. Also, five of the 16 categories are point estimates with no range. These categories include: (1) highly valued development, (2) ponderosa and sequoia for either management condition at low fire intensity, (3) Long-return interval conifers in maintenance condition at low fire intensity and (4) wildlife habitat in maintenance condition at high fire intensity. Anthropocentric values, such as developments (denoted by the solid triangle), boundaries (between public and private ownerships, denoted by the shaded triangle) and cultural and archaeological sites (denoted by the shaded box) were of high importance to protect from fire as shown by the range of -1.0 to -0.65 along the bottom of Fig. 1. Specifically, the cultural and archaeological sites were consistently important to protect as shown along the lower right side of Fig. 1.

While natural resources produced greater variation in valued fire effect, they were consistently judged to benefit from low-intensity fire events as all low-intensity observations had a value of 0.40 or greater. The high consistency of positive values from low-intensity fires in short- and long-return interval forests also reflects NPS policy direction [11]. A clear exception was for high-intensity fires in a restoration condition. Wildlife habitat provided the widest range of values in response to fire intensity as low fire intensity was evaluated to be beneficial and high-intensity fires were detrimental. While fire effects on nature's resources exhibited greater variation, their consistency in valuation by category also suggests the potential to consider the viability of generalized categories.

\section{CONCLUSIONS}

America's national parks contain some of the most treasured natural resources in the country and the world. Each national park is unique in its natural features and in its enabling purposes and legislation. Some parks contain unique forest cover types, such as the famous sequoia trees in California, while others are home to critical wildlife habitat, such as the northern 


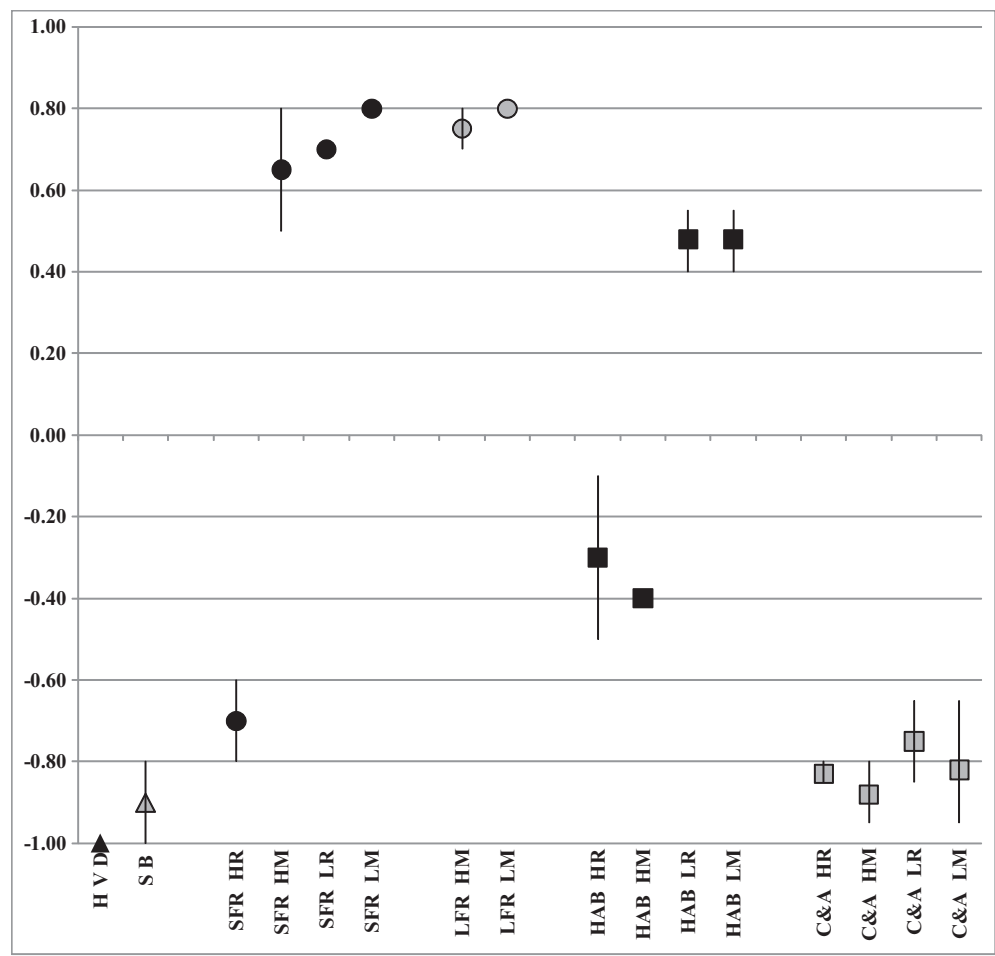

$\begin{array}{ll}\text { HVD } & \text { High value development } \\ \text { SB } & \text { Sensitive boundary } \\ \text { SFR HR } & \text { Short fire return interval, high restoration } \\ \text { SFR HM } & \text { Short fire return interval, high maintenance } \\ \text { SFR LR } & \text { Short fire return interval, low restoration } \\ \text { SFR LM } & \text { Short fire return interval, low maintenance } \\ \text { LFR } & \text { Long fire return interval, high maintenance } \\ \text { HM } & \\ \text { LFR LM } & \text { Long fire return interval, low maintenance } \\ \text { HAB } & \text { Wildlife habitat, high restoration } \\ \text { HR } & \\ \text { HAB } & \text { Wildlife habitat, high maintenance } \\ \text { HM } & \\ \text { HAB LR } & \text { Wildlife habitat, low restoration } \\ \text { HAB } & \text { Wildlife habitat, low maintenance } \\ \text { LM } & \\ \text { C\&A } & \text { Cultural and archaeological, high restoration } \\ \text { HR } & \\ \text { C\&A } & \text { Cultural and archaeological, high maintenance } \\ \text { HM } & \\ \text { C\&A } & \text { Cultural and archaeological, low restoration } \\ \text { LR } & \\ \text { C\&A } & \text { Cultural and archaeological, low maintenance } \\ \text { LM } & \end{array}$

Figure 1: Ranges and mid-points for meta-value attributes. 
Goshawk. Concurrently, the parks share a common sense of environmental purpose, value and management direction as stated in their set of management policies [11]. The NPS system with the uniqueness and diversity of parks and local values suggested that identifying generalized value categories would be challenging and subject to considerable variation. Further, exploration of marginal valuation across America's national parks with respect to fire management has not previously been approached using a quantitative framework.

Considering the first question regarding the viability of forming generalized categories, these parks provide descriptive evidence that forming generalized value categories could be fruitful. They have the potential to enable broader interpretation of marginal rates of substitution. Our small sample of parks precludes a formal meta-value analysis, but the descriptive analysis suggests that identifying generalized value categories may be promising. The second question regarding the consistency of valuation by category is addressed by sorting out the categories by return interval and management condition. Of particular interest is how distinguishing between long and short fire-return interval systems and ecosystem management condition improved interpretations across the parks. With this sorting, the consistency in valuation was remarkably similar across the four parks suggesting that generalized value categories have the potential to be useful descriptors when ecosystem management condition and return interval are addressed. When presented to national planners, this consistency was remarkable because most of the decisions requiring evaluation involve non-market resources for which little information is available. It was also not surprising to NPS officials as they strive to consistently implement their mission. Addressing these questions is of general interest in environmental and resource management as they can provide valuable insight and information for resource planning and environmental compliance beyond national parks. In particular, MARS can be applied to other public land types, such as national forests or national wildlife refuges.

Given that MARS was independently applied using four different 'expert' groups and locations, the consistency in elicited rates of substitution by generalized value category suggests that the results from MARS may be largely independent of the particular expert group. The consistency of values is shown by the tight ranges produced across the parks and by the fact that none of the ranges extended across zero. To the extent that the relative values are consistent, they may be useful at other parks to facilitate the valuation process as either a starting point for their own MARS valuation exercise or as a form of relative valuation transfer [12]. Parks initiating the marginal valuation process can use the value attributes to better identify their own specific planning unit level attributes. Replication at other national parks, particularly those not informally considered the 'crown jewels' of the park system is necessary before any general conclusions can be reached about similarity of fire-related marginal values at other units of the National Park System. To the extent that the reported relative values are consistent, they provide fire managers with guidance on resource trade-offs as they allocate scarce budget between competing uses. They also provide critical information for direct use in decision support systems that rely on coefficients to manage multiple objectives, as often such coefficients directly or indirectly imply marginal relative values.

\section{REFERENCES}

[1] U.S. Senate, Appropriations Bill, Department of the Interior, E., and Related Agencies, 2008.

[2] FEC (Fire Executive Council). Guidance for implementation of Federal Wildland Fire Management Policy. [cited 28 August 2009]; http://www.nifc.gov/policies/guidance/ GIFWFMP.pdf 
[3] Samuelson, P.A., The pure theory of Public Expenditure. Review of Economics and Statistics, 36, pp. 387-389, 1954. doi: http://dx.doi.org/10.2307/1925895

[4] Samuelson, P.A., Diagrammatic Exposition of a Theory of Public Expenditure. Review of Economics and Statistics, 37, pp. 350-356, 1955. doi: http://dx.doi.org/10.2307/ $\underline{1925849}$

[5] Champ, P.A., Boyle, K.J. \& Brown, T.C. (eds). A Primer on Nonmarket Valuation, Kluwer Academic Publishers: Dordrecht, The Netherlands, 2003.

[6] Holmes, T.P., Prestemon, J.P. \& Abt, K.L., An introduction to the economics of forest disturbance (Chapter 1), in The Economics of Forest Disturbances: Wildfires, Storms, and Invasive Species, eds T.P. Holmes, J.P. Prestemon \& K.L. Abt, Springer Science + Business Media B. V. pp. 3-14, 2008.

[7] Rideout, D.B., Ziesler, P.S., Kling, R., Loomis, J.B. \& Botti, S.J., Estimating rates of substitution for protecting values at risk for initial attack planning and budgeting. Forest Policy and Economics, 10, pp. 205-219, 2008. doi: http://dx.doi.org/10.1016/j.forpol. $\underline{2007.10 .003}$

[8] Shrestha, R., Rosenberger, R., \& Loomis, J.B., Benefit Transfer Using Meta-Analysis in Recreation Economic Valuation, in Benefit Transfer Accuracy: Meta-Analytic Review of the Literature, in Environmental Value Transfer: Issues and Methods, eds S. Navrud \& R. Ready, Springer: Dordrecht, The Netherlands, 2007.

[9] Review and Update of the 1995 Federal Wildland Fire Management Policy, National Interagency Fire Center, Boise, Idaho, 2001.

[10] Latinopoulos, D., Valuing the services of coastal ecosystems: a meta-analysis of contingent valuation studies. International Journal of Sustainable Development, 1, pp. 13-30, 2010.

[11] U.S. Department of the Interior National Park Service (NPS). Management Policies. [cited 18 July 2011]; http://www.nps.gov/policy/mp2006.pdf

[12] Rosenberger, R. \& Loomis, J.B., Benefit Transfer, in A Primer on Nonmarket Valuation, eds P.A. Champ, K.J. Boyle \& T.C. Brown, Kluwer Academic Publishers: Dordrecht, The Netherlands, 2003. doi: http://dx.doi.org/10.1007/978-94-007-0826-6 12 